\title{
Anticancer effects of marine carotenoids, fucoxanthin and its deacetylated product, fucoxanthinol, on osteosarcoma
}

\author{
TAKAYOSHI ROKKAKU ${ }^{1,2}$, RYUICHIRO KIMURA ${ }^{1,3}$, CHIE ISHIKAWA $^{1,3}$, TAKESHI YASUMOTO $^{4}$, \\ MASACHIKA SENBA $^{5}$, FUMINORI KANAYA ${ }^{2}$ and NAOKI MORI ${ }^{1}$ \\ Departments of ${ }^{1}$ Microbiology and Oncology and ${ }^{2}$ Orthopedic Surgery, Graduate School of Medicine, \\ University of the Ryukyus, Nishihara, Okinawa 903-0215; ${ }^{3}$ Transdisciplinary Research Organization for Subtropics \\ and Island Studies, University of the Ryukyus, Nishihara, Okinawa 903-0213; ${ }^{4}$ Marine Bio Industry Division, \\ Okinawa Science and Technology Promotion Center, Naha, Okinawa 900-0029; ${ }^{5}$ Department of Pathology, \\ Institute of Tropical Medicine, Nagasaki University, Nagasaki 852-8523, Japan
}

Received April 25, 2013; Accepted June 7, 2013

DOI: $10.3892 /$ ijo.2013.2019

\begin{abstract}
Survival of osteosarcoma patients hinges on prevention or treatment of recurrent and metastatic lesions. Therefore, novel chemotherapeutics for more effective treatment and prevention of this disease are required. Carotenoids are natural pigments and exhibit various biological functions. We evaluated the anti-osteosarcoma properties of several carotenoids. Among carotenoids, fucoxanthin and its metabolite fucoxanthinol, inhibited the cell viability of osteosarcoma cell lines. Fucoxanthinol induced $\mathrm{G}_{1}$ cell cycle arrest by reducing the expression of cyclin-dependent kinase 4, cyclindependent kinase 6 and cyclin $\mathrm{E}$ and apoptosis by reducing the expression of survivin, XIAP, Bcl-2 and Bcl- $\mathrm{x}_{\mathrm{L}}$. Apoptosis was associated with activation of caspases-3, -8 and -9 . In addition, fucoxanthinol inhibited the phosphorylation of phosphoinositide-dependent kinase 1 and Akt and the downstream glycogen synthase kinase $3 \beta$, resulting in downregulation of $\beta$-catenin. Fucoxanthinol inhibited the cell migration and invasion of osteosarcoma cells. It also reduced matrix metalloproteinase-1 expression and the activator protein-1 signal. Treatment of mice inoculated with osteosarcoma cells with fucoxanthin inhibited the development of osteosarcoma in mice. Fucoxanthin and fucoxanthinol inhibit cell growth, migration and invasion and induce apoptosis of osteosarcoma cells at least in part by inhibiting Akt and activator protein-1 pathways. Our findings provide a rationale for clinical evaluation of these novel agents in osteosarcoma.
\end{abstract}

Correspondence to: Professor Naoki Mori, Department of Microbiology and Oncology, Graduate School of Medicine, University of the Ryukyus, 207 Uehara, Nishihara, Okinawa 903-0215, Japan E-mail: naokimori50@gmail.com

Key words: fucoxanthin, fucoxanthinol, osteosarcoma, Akt, activator protein-1, matrix metalloproteinase-1

\section{Introduction}

Osteosarcoma is the most frequent malignant bone tumor in children and adolescents and the estimated worldwide incidence ranges between 3 and 4.5 per million (1). Long-term survival in localized osteosarcoma has increased substantially from $10-20 \%$ when surgery as single treatment was used before the 1980's up to 20-60\% from 1985 onwards. The improvement in survival has been attributed to the use of intensive multiagent chemotherapy in combination with advanced surgery. However, since then no substantial further improvement of survival has been reported (2). Despite aggressive multimodal therapy, this devastating tumor often acquires drug resistance and metastasizes (3). The most frequent site for metastatic presentation is the lung (3). Death from osteosarcoma is usually the result of progressive pulmonary metastasis with respiratory failure due to widespread disease (3). Hence, there is a real need to develop novel approaches for the treatment and prevention of osteosarcoma and efficient inhibition of metastasis, especially to the lung.

The role of carotenoids in reducing the risk of cancer has been postulated for several decades (4). Fucoxanthin, one of the most abundant carotenoids found in edible brown algae, has received much attention over the last few years as cancer chemopreventive and chemotherapeutic agent (5). Dietary fucoxanthin is deacetylated into fucoxanthinol in the intestinal tract by lipase and esterase from the pancreas or in intestinal cells and incorporated as fucoxanthinol from the digestive tract into the blood circulation system in mammals (5). These carotenoids exhibit antitumor effects in several malignant cell lines without affecting normal cells $(5,6)$. The main mechanism is suggested to be the regulatory effects of fucoxanthin and fucoxanthinol on molecules related to apoptosis and cell cycle $(5,6)$. Furthermore, it has been shown that fucoxanthin has chemopreventive activities in a variety of models of cancer (5). However, to date, there is no information on fucoxanthin- and fucoxanthinol-induced inhibition of cell growth, migration and invasion of human bone cancer cells. In this study, we investigated the effects of fucoxanthin and 
fucoxanthinol on cell cycle, apoptosis, migration and invasion of osteosarcoma cells. Furthermore, we also investigated the possible molecular targets of anti-osteosarcoma activities of fucoxanthin and fucoxanthinol.

\section{Materials and methods}

Cell lines. The human osteosarcoma cell lines, Saos-2, MNNG/ HOS (MNNG) and 143B and mouse osteosarcoma cell line, LM8, were cultured in Roswell Park Memorial Institute-1640 or Eagle's minimum essential medium supplemented with $10 \%$ heatinactivated fetal bovine serum (FBS), $50 \mathrm{U} / \mathrm{ml}$ penicillin and $50 \mu \mathrm{g} / \mathrm{ml}$ streptomycin at $37^{\circ} \mathrm{C}$ in a humidified atmosphere with $5 \% \mathrm{CO}_{2}$. Both $143 \mathrm{~B}$ cell line with high metastatic potential and MNNG cell line with low metastatic potential, are derived from TE85 human osteosarcoma cell line $(7,8)$.

Reagents. $\beta$-carotene and astaxanthin were purchased from Wako Pure Chemical Industries (Osaka, Japan). Fucoxanthin was extracted from brown seaweed Cladosiphon okamuranus Tokida using acetone as solvent and purified by column chromatography, liquid-liquid partition and re-crystallization up to $>95 \%$ purity. Further purification was performed by RP-HPLC up to $>98 \%$ purity, for in vitro assay. Fucoxanthinol was prepared by enzymatic hydrolysis of purified fucoxanthin using porcine pancreatic lipase. For this purpose, $195 \mathrm{mg}$ of fucoxanthin, $2 \mathrm{~g}$ of sodium taurocholate and $2 \mathrm{~g}$ of porcine pancreatic lipase (Type II; Sigma-Aldrich, St. Louis, MO, USA) were dissolved in $30 \mathrm{ml}$ of $0.1 \mathrm{M}$ sodium phosphate buffer (pH 7.0). The reaction buffer was incubated at $37^{\circ} \mathrm{C}$ for $3 \mathrm{~h}$. Fucoxanthinol was purified by ODS column chromatography, liquid-liquid partition and re-crystallization. In the experiment, we prepared $142 \mathrm{mg}$ of purified fucoxanthinol (>95\% purity, $72 \%$ yield). Further purification was achieved by RP-HPLC up to $>98 \%$ purity, for in vitro assay. The identity and purity of the products were confirmed by comparison with reference fucoxanthin (Wako Pure Chemical Industries) and data available in the literature. Tumor necrosis factor- $\alpha$ (TNF- $\alpha$ ) and the caspase inhibitor, Z-VAD-fmk, were purchased from PeproTech (Rocky Hill, NJ, USA) and Promega (Madison, WI, USA), respectively. Antibodies to Bcl-2, cyclin E, cyclindependent kinase (CDK)2, CDK4, CDK6 and actin were purchased from NeoMarkers (Fremont, CA, USA). Antibodies to XIAP and cyclin D1 were obtained from Medical and Biological Laboratories (Nagoya, Japan). Antibodies to I $\mathrm{B} \alpha$, phospho-IкB $\alpha$ (Ser32 and Ser36), Akt, phospho-Akt (Thr308), phospho-Akt (Ser473), phosphoinositide-dependent kinase 1 (PDK1), phospho-PDK1 (Ser241), phospho-glycogen synthase kinase $3 \beta$ (GSK3 $\beta$ ) (Ser9), caspase-8, cleaved caspase-3, cleaved caspase-9, cleaved poly(ADP-ribose) polymerase (PARP), phospho-caspase-9 (Thr125), survivin, Bak and Bcl- $\mathrm{x}_{\mathrm{L}}$ were purchased from Cell Signaling Technology (Beverly, MA, USA). Antibodies to GSK3 $\beta$ and $\beta$-catenin were obtained from BD Transduction Laboratories (San Jose, CA, USA). Antibodies to cyclin D2, phospho-p130 (Ser952) and activator protein-1 (AP-1) subunits c-Fos, FosB, Fra-1, Fra-2, c-Jun, JunB and JunD for super-shift assay were purchased from Santa Cruz Biotechnology (Santa Cruz, CA, USA). Antibody to matrix metalloproteinase-1 (MMP-1) was purchased from Daiichi Fine Chemical (Takaoka, Japan).
Cell culture, viability and apoptosis assays. For the viability assay, the cell lines were plated in 96-well culture plates for $24 \mathrm{~h}$ in complete culture medium. Different concentrations of each carotenoid were added and the cells were incubated for $24 \mathrm{~h}$. Cell viability was evaluated by measuring the mitochondrial-dependent conversion of the water-soluble tetrazolium (WST)-8 (Nacalai Tesque, Kyoto, Japan) to a colored formazan product. WST-8 $(5 \mu \mathrm{l})$ was added for the last $4 \mathrm{~h}$ of incubation and absorbance at $450 \mathrm{nM}$ was measured using an automated microplate reader. Apoptotic events in cells were detected by staining with phycoerythrin-conjugated Apo2.7 antibody (Beckman Coulter, Marseille, France) (9) and analyzed by flow cytometry (Epics XL, Beckman Coulter, Fullerton, CA, USA). Since the viability of $20 \mu \mathrm{M}$ fucoxanthinol-treated Saos- 2 cells at $24 \mathrm{~h}$ was $0 \%$, electrophoretic mobility shift and protein expression assays were carried out at 9-12 $\mathrm{h}$ for incubation.

Assessment of caspase activities. After treatment with indicated concentrations of fucoxanthinol $(5,10$ and $20 \mu \mathrm{M})$ for $9 \mathrm{~h}$, the activities of caspases-3/7, -8 and -9 were evaluated, respectively, using Caspase-Glo 3/7, 8 and 9 assay kits (Promega) according to the manufacturer's protocol. The luminescence that is proportional to caspases-3/7, -8 and -9 activities was determined by a luminometer.

Cell cycle analysis. Cells were treated with fucoxanthinol at a concentration of $20 \mu \mathrm{M}$. After $9 \mathrm{~h}$ of incubation, cell cycle analysis was performed with the CycleTest Plus DNA reagent kit (Becton-Dickinson Immunocytometry Systems, San Jose, CA, USA). Briefly, cells were washed with a buffer solution containing sodium citrate, sucrose and DMSO, suspended in a solution containing RNase A and then stained with $125 \mu \mathrm{g} / \mathrm{ml}$ propidium iodide for $10 \mathrm{~min}$. Cell suspensions were analyzed on a Coulter EPICS XL using EXPO32 software. The population of cells in each cell cycle was determined with the MultiCycle software.

Reverse transcription-PCR (RT-PCR). Total cellular RNA from cells was extracted with TRIzol (Invitrogen, Carlsbad, CA, USA) according to the protocol provided by the manufacturer. First-strand cDNA was synthesized from $1 \mu \mathrm{g}$ total cellular RNA using a PrimeScript RT-PCR kit (Takara Bio Inc., Otsu, Japan) with random primers. The primers used were 5'-GGTGCCCAGTGGTTGAAAAAT-3' (forward) and 5'-CATCACTTCTCCCCGAATCGT-3' (reverse) for MMP-1 and 5'-GCCAAGGTCATCCATGACAACTTTGG-3' (forward) and 5'-GCCTGCTTCACCACCTTCTTGATGTC-3' (reverse) for glyceraldehyde 3-phosphate dehydrogenase (GAPDH). The length of RT-PCR was 40 cycles for MMP-1 and 27 cycles for GAPDH. The PCR products were fractionated on $2 \%$ agarose gels and visualized by ethidium bromide staining.

Western blot analysis. Cells were lysed in a buffer containing

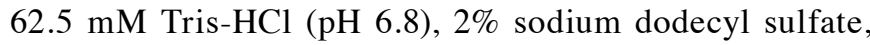
$10 \%$ glycerol, $6 \%$ 2-mercaptoethanol and $0.01 \%$ bromophenol blue. Equal amounts of protein $(20 \mu \mathrm{g})$ were subjected to electrophoresis on sodium dodecyl sulfate-polyacrylamide gels, followed by transfer to a polyvinylidene difluoride membrane and sequential probing with the specific antibodies. The bands 
were visualized with an enhanced chemiluminescence kit (Amersham Biosciences, Piscataway, NJ, USA).

Preparation of nuclear extracts and electrophoretic mobility shift assay (EMSA). Nuclear extracts were obtained as described by Antalis and Godbolt (10) with modifications and EMSA was performed as described previously (11). Briefly, $5 \mu \mathrm{g}$ of nuclear extract was incubated with ${ }^{32} \mathrm{P}$-labeled probes. The DNA-protein complex was separated from the free oligonucleotides on $4 \%$ polyacrylamide gel. To examine the specificity of the probe, we preincubated unlabeled competitor oligonucleotides with nuclear extracts for $15 \mathrm{~min}$ before incubation with probes. The probes or competitors used were prepared by annealing the sense and antisense synthetic oligonucleotides as follows: for the wild-type AP-1 element of the MMP-1 gene, 5'-GATCTTATAAAGCATGAGTCAGACACCTCT-3'; for the AP-1 element mutant of the MMP-1 gene, 5'-GATCTTAT AAAGCATGAtggAGACACCTCT-3' (sites of mutation are indicated in lowercase); for the AP-1 element of the interleukin (IL)-8 gene, 5'-GATCGTGATGACTCAGGTT-3'; and for the nuclear factor $-\kappa \mathrm{B}(\mathrm{NF}-\kappa \mathrm{B})$ element of the IL-2 receptor $\alpha$ chain (IL-2R $\alpha$ ) gene, 5'-GATCCGGCAGGGGAATCTCC CTCTC-3'. The oligonucleotide 5'-GATCTGTCGAATGC AAATCACTAGAA-3', containing the consensus sequence of the octamer binding motif, was used to identify specific binding of the transcription factor, Oct-1. The underlined sequences above are the AP- $1, \mathrm{NF}-\kappa \mathrm{B}$ and Oct- 1 binding sites, respectively. To identify transcription factors in the DNA-protein complex detected by EMSA, we used antibodies specific for various AP-1 family proteins, including c-Fos, FosB, Fra-1, Fra-2, c-Jun, JunB and JunD (Santa Cruz Biotechnology), to elicit a supershift DNA-protein complex formation. These antibodies were incubated with the nuclear extracts for $45 \mathrm{~min}$ at room temperature before incubation with radiolabeled probe.

Cell invasion assay. ACEA electrosensing x16 microtiter plates were coated with $215 \mu \mathrm{g} / \mathrm{ml}$ rat tail type I collagen (BD Biosciences, San Jose, CA, USA). Saos-2 cells were seeded at $3 \times 10^{5}$ cells $/ \mathrm{ml}$ in $100 \mu \mathrm{l}$ of serum-free medium without or with fucoxanthinol (50 or $100 \mathrm{nM}$ ) in the upper chamber with $8-\mu \mathrm{m}$ pore size and the lower chamber contained $10 \%$ serum. The ACEA plate was connected to the ACEA Device Station at $37^{\circ} \mathrm{C}$ and the cells that invaded through type I collagen were monitored every $1 \mathrm{~h}$ in real-time by an ACEA Sensor Analyzer for $24 \mathrm{~h}$ and quantitated using ACEA RT-CES Integrated software.

Cell migration assay. Saos- 2 cell migration was also assessed using ACEA electrosensing x16 microtiter plates. Saos-2 cells were seeded at $3 \times 10^{5}$ cells $/ \mathrm{ml}$ in $100 \mu \mathrm{l}$ of serum-free medium without or with fucoxanthinol (625 or 1,250 nM) in the upper chamber with $8-\mu \mathrm{m}$ pore size and the lower chamber contained serum-free medium supplemented with $50 \mathrm{ng} / \mathrm{ml}$ recombinant human stromal cell-derived factor- $1 \alpha$ (SDF-1 $\alpha$ ) (PeproTech Inc.). The ACEA plate was connected to the ACEA Device Station at $37^{\circ} \mathrm{C}$ and migrated cells were monitored every $1 \mathrm{~h}$ in real time by the ACEA Sensor Analyzer for $6 \mathrm{~h}$ and quantitated using ACEA RT-CES Integrated software.
Transplant metastasis of LM8 tumor cells in mice. A mouse osteosarcoma cell line, LM8 cells $\left(5 \times 10^{6}\right.$ cells/mouse $)$ in $0.1 \mathrm{ml}$ phosphate buffered saline was injected subcutaneously into the back of 5-week-old female C3H mice (Japan SLC, Hamamatsu, Japan) on day 0 . Treatment was initiated on the day after cell injection. Fucoxanthin was dissolved in soybean oil and $200 \mathrm{mg} /$ $\mathrm{kg}$ of fucoxanthin or vehicle only was given by oral gavage every day for 35 days. The mice were weighed once a week and the size of the primary tumor was measured weekly. Mice were also monitored for evidence of morbidity including anorexia, dehydration, dyspnea, decreased activity and grooming behavior. On day 35, all mice were euthanized and autopsied to confirm metastatic lung disease. Lung sections were prepared and the area of lung metastasis was measured. Primary tumors were dissected out for measurement of weight and staining with hematoxylin and eosin (H\&E) and terminal deoxynucleotidyl transferase-mediated dUTP nick-end labeling (TUNEL) using a commercial kit (Roche Applied Science, Mannheim, Germany). This experiment was performed according to the Guidelines for Animal Experimentation of the University of the Ryukyus and was approved by the Animal Care and Use Committee of the University of the Ryukyus (permit mumbers: 5150, 5274 and 5338).

Statistical analysis. Data were expressed as mean \pm SD. Differences between groups were examined for statistical significance using the unpaired Student's t-test. A $\mathrm{P}<0.05$ denoted the presence of a statistically significant difference.

\section{Results}

Effect of fucoxanthin and fucoxanthinol on osteosarcoma cell viability. We first examined the effects of carotenoids on the cell viability of osteosarcoma cell lines. Fucoxanthin and fucoxanthinol used in this study reduced cell viability of all 4 osteosarcoma cell lines in a dose-dependent manner (Fig. 1A and B). In contrast, the effects of other carotenoids, $\beta$-carotene and astaxanthin, were less significant, although $\beta$-carotene reduced LM8 cell viability at $30 \mu \mathrm{M}$ concentration (Fig. 1C and D).

Caspase-dependent induction of apoptosis by fucoxanthinol. The apoptosis-inducing activity of fucoxanthinol was analyzed by immunostaining with Apo2.7, which specifically detects the 38-kDa mitochondrial membrane antigen, 7A6, expressed on the mitochondrial outer membrane during apoptosis (9). The proportion of 7A6-positive cells among Saos-2 cells incubated for $9 \mathrm{~h}$ without fucoxanthinol was $0.3 \%$, but increased to $34.9 \%$ when the cells were treated with $20 \mu \mathrm{M}$ fucoxanthinol (Fig. 2A). We next investigated the role of caspases in fucoxanthinol-induced apoptosis by measuring the cleavage of known caspase substrates by immunoblot analysis. Fucoxanthinol cleaved the caspase-3-specific substrate, PARP, in Saos- 2 cells in a time- and dose-dependent manner. In addition, fucoxanthinol processed the initiator caspases-8 and -9 and the executioner caspase- 3 in Saos- 2 cells in a time- and dose-dependent manner (Fig. 2B). We also investigated whether fucoxanthinol can activate the caspases by examining protease activity using fluorescence substrates specific for caspases-3/7, -8 and -9 . As shown in Fig. 3A, after treatment 
A

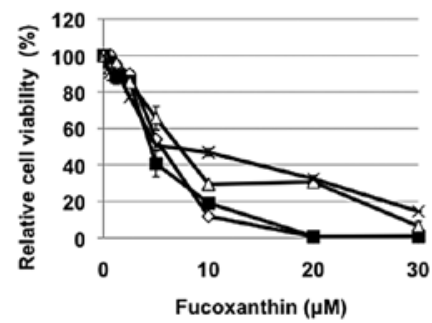

C

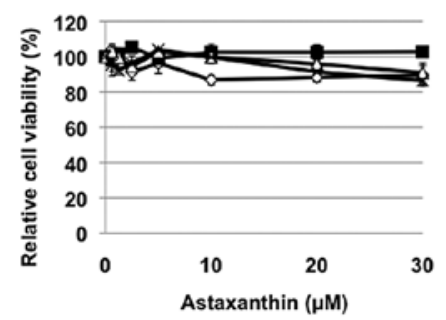

B

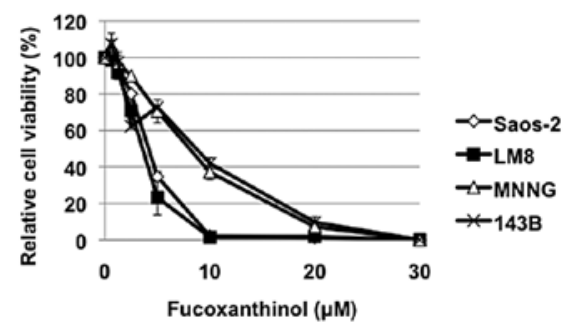

D

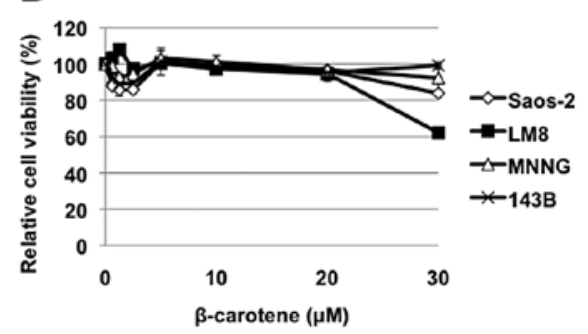

Figure 1. Effects of carotenoids on viability of osteosarcoma cell lines. Viability of the indicated osteosarcoma cell lines treated for $24 \mathrm{~h}$ with fucoxanthin (A), fucoxanthinol (B), astaxanthin (C) and $\beta$-carotene (D) at the noted concentrations was analyzed by the WST- 8 assay. Cell viability is expressed as the percentage of cell survival compared with the control. Values are mean $\pm \operatorname{SD}(n=3)$.

A

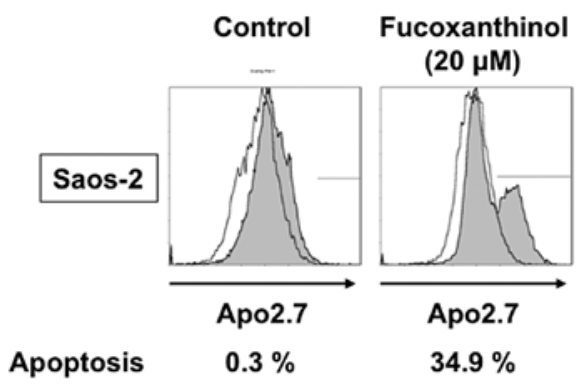

B

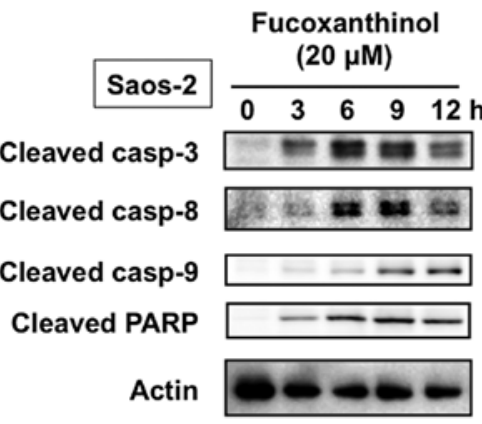

Figure 2. Apoptosis-inducing activity of fucoxanthinol in Saos-2 cells. (A) Saos-2 cells were incubated with or without fucoxanthinol $(20 \mu \mathrm{M})$ After $9 \mathrm{~h}$, the cells were either stained with phycoerythrin-conjugated antiApo2.7 antibody (gray/solid) or an isotype control phycoerythrin antibody (lines/open) and subjected to flow cytometry. (B) Fucoxanthinol induced caspase-dependent apoptosis of Saos-2 cells. The cells were treated with fucoxanthinol $(20 \mu \mathrm{M})$ for the indicated time intervals (left) and were treated with the indicated concentrations of fucoxanthinol for $9 \mathrm{~h}$ (right). Then, cellular proteins were subjected to gel electrophoresis followed by immunoblot analysis and chemiluminescence detection as described in Materials and methods. Caspase activity was determined by the production of PARP, caspases- $3,-8$ and -9 cleavage products.

with fucoxanthinol for $9 \mathrm{~h}$, the activities of caspases-3/7, -8 and -9 were all obviously increased in a dose-dependent manner compared with controls.

To investigate further the involvement of the caspase pathway, Saos-2 cells were treated with a broad spectrum caspase inhibitor, Z-VAD-fmk, together with fucoxanthinol. Saos-2 cell treatment with fucoxanthinol decreased the activities of caspases-3/7, -8 and -9 after adding Z-VAD-fmk (Fig. 3A). As shown in Fig. 3B, reduced cell viability induced by fucoxanthinol was significantly diminished by Z-VAD-fmk. These results indicate that fucoxanthinol-induced apoptosis of Saos-2 cells is mediated through caspase activation.

Fucoxanthinol causes $G_{l}$ cell cycle arrest. We also examined the distribution of cellular DNA contents by flow cytometric analysis. Cultivation of Saos-2 and LM8 cells with $20 \mu \mathrm{M}$ fucoxanthinol for $9 \mathrm{~h}$ increased the population of the cells in the $G_{1}$ phase, with marked reduction of the $S$ phase, relative to untreated cells (Fig. 4). These results indicate that, together with induction of apoptosis, fucoxanthinol induces $\mathrm{G}_{1}$ cell cycle arrest in osteosarcoma cells.

Effects of fucoxanthinol on the expression of cell cycle regulatory proteins. $\mathrm{G}_{1}-\mathrm{S}$ progression is influenced by diverse growth signaling pathways that converge on the control of CDK, including CDK4 or CDK6 in conjunction with D type cyclins and CDK2 in conjunction with cyclin $\mathrm{E}$ (12). The best characterized substrates of $\mathrm{G}_{1} \mathrm{CDKs}$ are the retinoblastoma protein $(\mathrm{pRB})$ and the $\mathrm{pRB}$-related proteins, $\mathrm{p} 107$ and p130 (12). Each of these pRB family members can block the progression from $\mathrm{G}_{1}$ into $\mathrm{S}$ and is thought to do so, at least in part, by binding to E2F transcription factors and repressing genes that contribute to $S$ phase entry (12). These pRB family proteins are phosphorylated and released from E2Fs in the late $\mathrm{G}_{1}$ phase of the cell cycle (12). In pRB (-) Saos-2 cells, p130 but not p107 was phosphorylated and released from E2F-4 in a CDK2-dependent process in late $\mathrm{G}_{1}$ and $\mathrm{S}$ phase cells (13). 
A

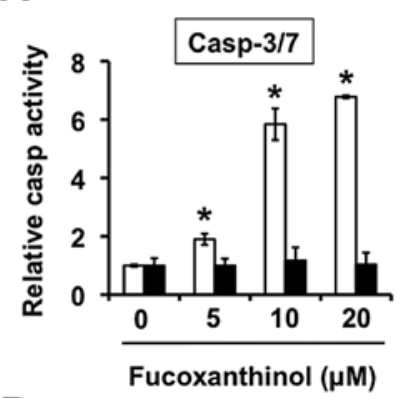

B

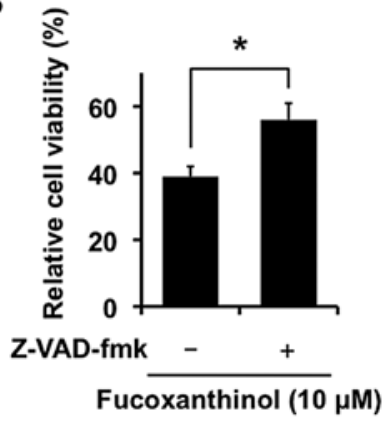

Control Z-VAD-fmk
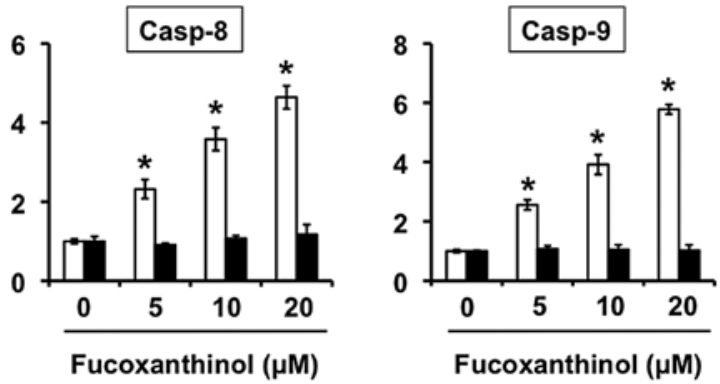

Figure 3. Effects of the caspase inhibitor Z-VAD-fmk. (A) Effects of treatment with fucoxanthinol alone or fucoxanthinol and Z-VAD-fmk together on caspases-3/7, -8 and -9 activities in Saos-2 cells. Saos-2 cells were treated with the indicated concentrations of fucoxanthinol for $9 \mathrm{~h}$. Pretreatment with Z-VAD-fmk at the concentration of $20 \mu \mathrm{M}$ for $1 \mathrm{~h}$ prior to exposure to fucoxanthinol was conducted. Caspase activities are expressed relative to each control group, which was assigned an arbitary value of 1 . Values are mean \pm SD ( $=3)$. The asterisk indicates a value significantly different from the control (Saos-2 cells incubated without fucoxanthinol) value $(\mathrm{P}<0.05)$. (B) Effect of Z-VAD-fmk on reduced cell viability in Saos- 2 cells induced by fucoxanthinol. Saos-2 cells were incubated in culture medium containing $10 \mu \mathrm{M}$ fucoxanthinol for $24 \mathrm{~h}$. Pretreatment with Z-VAD-fmk at the concentration of $20 \mu \mathrm{M}$ for $1 \mathrm{~h}$ prior to exposure to fucoxanthinol was conducted. Cell viability is expressed as the percentage of cell survival compared with the control. Values are mean $\pm \mathrm{SD}$ ( $\mathrm{n}=3$ ). ${ }^{*} \mathrm{P}<0.05$.

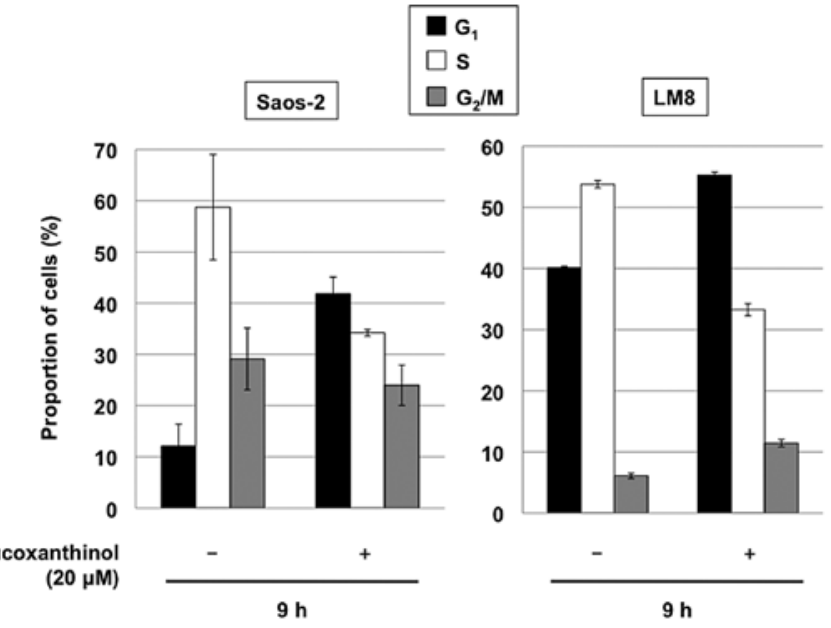

Figure 4. Effects of fucoxanthinol on cell cycle in Saos-2 and LM8 cells. The cells were treated with or without fucoxanthinol $(20 \mu \mathrm{M})$ for $9 \mathrm{~h}$. Cell cycle distribution was analyzed by flow cytometry following staining with propidium iodide. Data are expressed as mean \pm SD percentage of cells at various phases of the cell cycle $(n=3)$.

To clarify the molecular mechanism of fucoxanthinolinduced $\mathrm{G}_{1}$ cell cycle arrest, we investigated its effects on the expression of several intracellular regulators of cell cycle by western blot analysis. As shown in Fig. 5A, fucoxanthinol significantly reduced the expression of CDK4, CDK6 and cyclin $\mathrm{E}$ in Saos-2 cells in a time-dependent manner, but had no effect on CDK2, cyclin D1 and cyclin D2 expression levels. Furthermore, fucoxanthinol inhibited phosphorylation of p130. Comparable loading of protein was confirmed with a specific antibody for the housekeeping gene product actin (Fig. 5A). These results indicate that fucoxanthinol dephosphorylates p130 by inhibiting the expression of CDK4, CDK6 and cyclin $E$, resulting in $G_{1}$ cell cycle arrest.

Effects of fucoxanthinol on the expression of apoptosis regulatory proteins. To elucidate the possible molecular targets of fucoxanthinol-induced apoptosis of Saos-2 cells, we examined the expression of important apoptosis regulators. As shown in Fig. 5B, fucoxanthinol potently reduced the expression of anti-apoptotic proteins survivin, XIAP, Bcl-2 and $\mathrm{Bcl}-\mathrm{X}_{\mathrm{L}}$ in a time- and dose-dependent manner, but had no effect on proapoptotic protein Bak.

Inhibitory effects of fucoxanthinol on Akt activation. Members of the NF- $\kappa \mathrm{B}$ family control the expression of several genes that regulate cell survival, proliferation and apoptosis (14). NF- $\kappa \mathrm{B}$ is inactive in the cytosol because it is bound to $\mathrm{I} \kappa \mathrm{B} \alpha$ and becomes active after $\mathrm{I} \kappa \mathrm{B} \alpha$ has been phosphorylated and subsequently degraded (15). Because CDK4, CDK6, cyclin E, survivin, XIAP, Bcl-2 and Bcl- $\mathrm{x}_{\mathrm{L}}$ are controlled by $N F-\kappa B(16-22)$, we determined the effects of fucoxanthinol on the phosphorylation and degradation of $\mathrm{I} \kappa \mathrm{B} \alpha$. As shown in Fig. 5B, treatment of Saos-2 cells with fucoxanthinol did not affect the level of total I $\kappa \mathrm{B} \alpha$. In addition, phosphorylated $\mathrm{I} \kappa \mathrm{B} \alpha$ could not be detected in untreated or fucoxanthinol-treated Saos-2 cells (Fig. 5B). The activation of NF- $\kappa$ B in Saos- 2 cells in response to TNF- $\alpha$ stimulus 


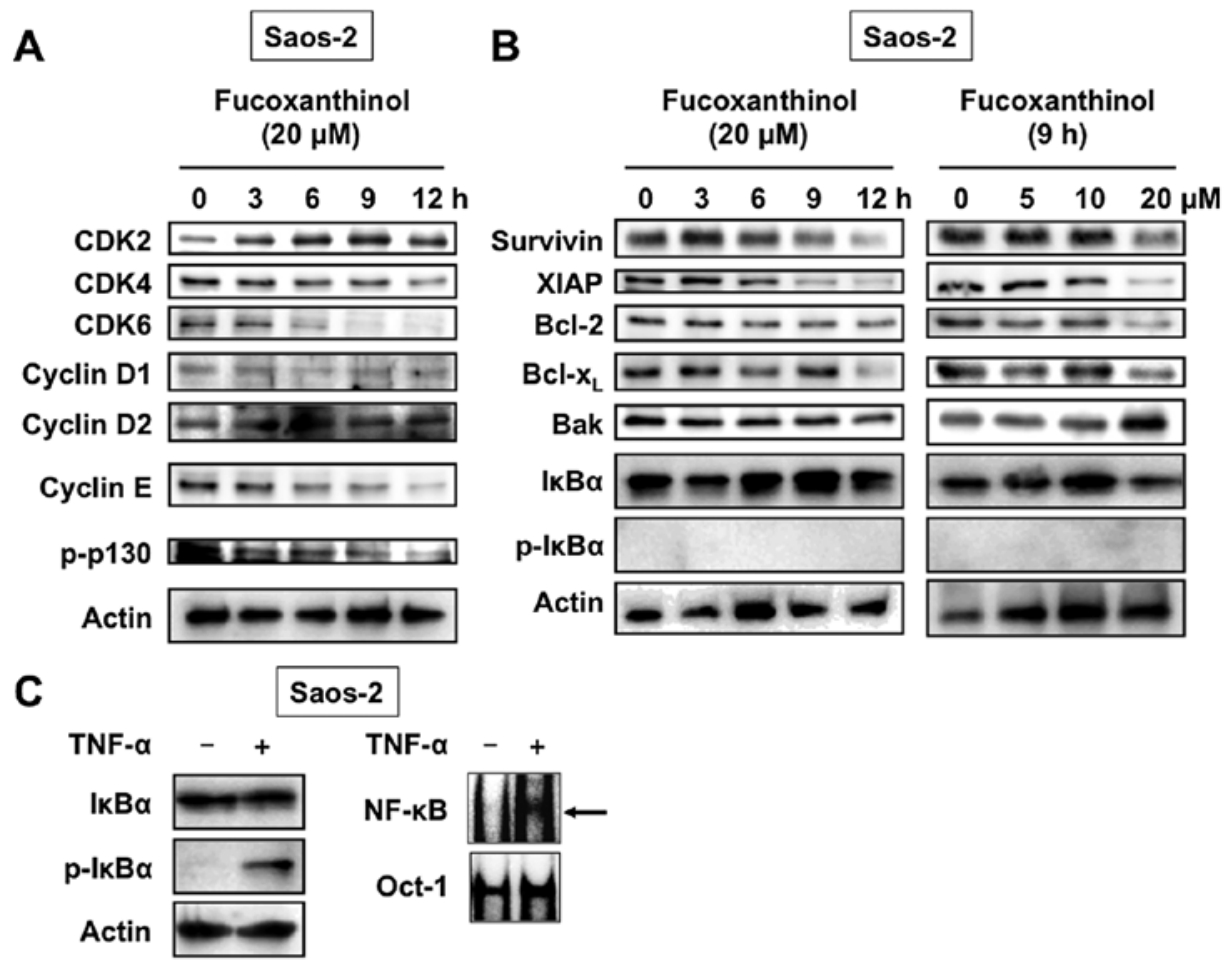

Figure 5. Effects of fucoxanthinol on expression of cell cycle and apoptosis regulatory proteins and NF-кB activity. (A and B) Western blot analysis for cell cycle and apoptosis regulatory proteins and IкB $\alpha$ in Saos-2 cells. Representative changes in the expression of these proteins after treatment with various concentrations of fucoxanthinol for the indicated time intervals. As loading control, actin protein expression was included. (C) Effect of TNF- $\alpha$ on the

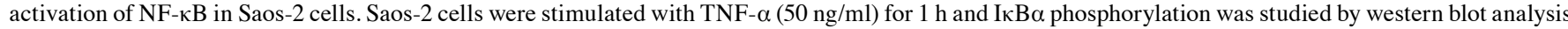
(left panels). EMSA of nuclear extracts $(5 \mu \mathrm{g})$ from Saos-2 cells cultured in the absence or presence of TNF- $\alpha$ (50 $\mathrm{ng} / \mathrm{ml})$ for $1 \mathrm{~h}$ (right panels). Arrow, specific NF-кB-DNA binding complex.

was assessed by western blotting and EMSA. EMSA detects nuclear factor binding to a specific consensus NF- $\kappa B$ sequence. As shown in Fig. 5C, treatment of Saos-2 cells with TNF- $\alpha$ resulted in increases in I $\kappa \mathrm{B} \alpha$ phosphorylation and NF-кB-DNA binding, while basal levels of phosphorylated I $\kappa \mathrm{B} \alpha$ as well as NF- $\mathrm{kB}$-DNA binding were not observed in Saos- 2 cells. These results show that fucoxanthinol does not affect NF- $\mathrm{kB}$ activation.

The phosphatidylinositol 3-kinase (PI3K)-Akt pathway also plays an important role in various cellular processes including cell growth and survival in osteosarcoma cells (23). Akt prevents apoptosis by activating anti-apoptotic signals by phosphorylating GSK $3 \beta$ and caspase- 9 and by activating NF- $\mathrm{BB}$ (24). To determine whether the Akt activity is associated with the apoptotic effects of fucoxanthinol, we examined the protein expression and phosphorylation level of Akt after fucoxanthinol treatment. Akt was constitutively activated in Saos-2 cells and fucoxanthinol decreased the phosphorylation level of Akt at both Thr308 and Ser473 sites (Fig. 6).

We next examined the effect of fucoxanthinol on the phosphorylation levels of two Akt downstream targets: GSK3 $\beta$ and caspase-9, in Saos-2 cells. As shown in Fig. 6, constitutive phosphorylation of GSK3 $\beta$ and caspase-9 was seen in Saos-2 cells and fucoxanthinol reduced the phosphorylation level. A key downstream target of GSK3 $\beta$ is the proto-oncogene, $\beta$-catenin. Fucoxanthinol inhibited GSK $3 \beta$ phosphorylation, thereby maintaining GSK $3 \beta$ in its active form. Active GSK $3 \beta$ induced $\beta$-catenin phosphorylation, resulting in increased ubiquitin-mediated proteolysis and decreased levels

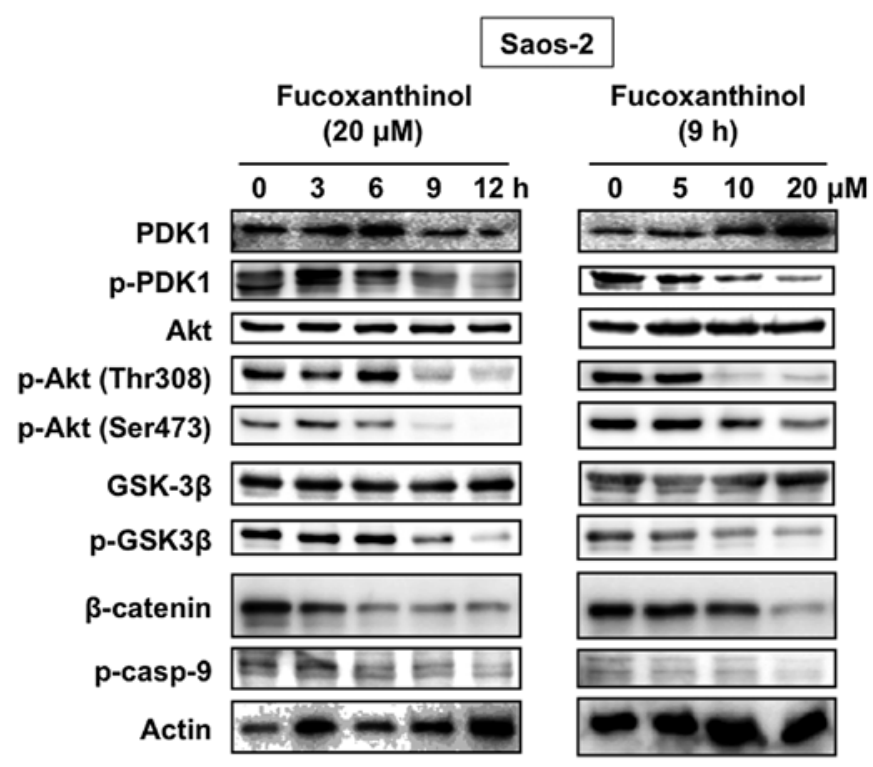

Figure 6. Fucoxanthinol inhibited constitutively active Akt signaling pathway in Saos-2 cells. Saos-2 cells were treated with the noted concentrations of fucoxanthinol for the indicated time intervals. Equal amounts of protein from each sample were separated on sodium dodecyl sulfate-polyacrylamide gels and immunoblotted with specific antibodies.

of signaling-competent $\beta$-catenin. Fucoxanthinol reduced the levels of $\beta$-catenin in Saos-2 cells (Fig. 6). Akt is phosphorylated at Thr308 in the kinase activation loop mediated by 
A

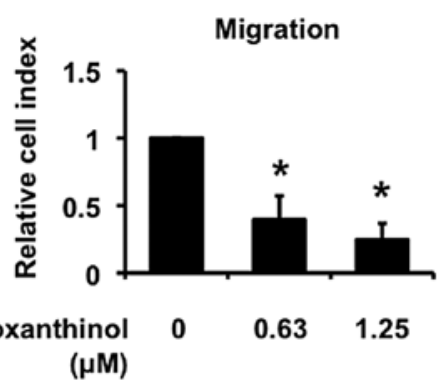

C

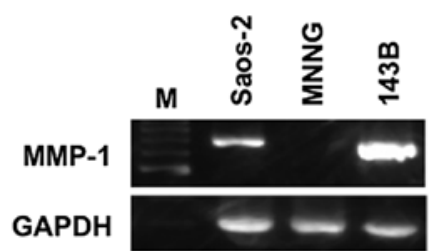

B

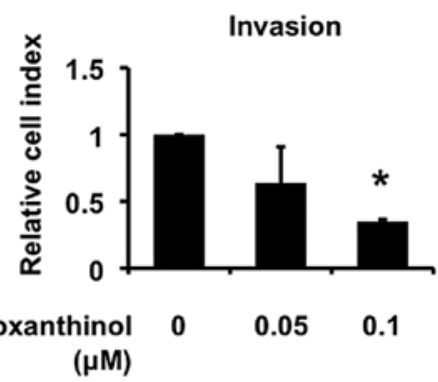

D

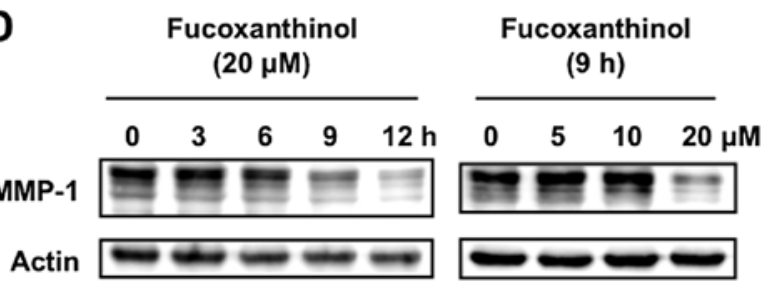

Figure 7. Fucoxanthinol influenced migration and invasion of Saos-2 cells in vitro. (A) Fucoxanthinol inhibited SDF-1 $\alpha$-induced migration of Saos-2 cells. Cells were treated with the indicated concentrations of fucoxanthinol followed by stimulation with $50 \mathrm{ng} / \mathrm{ml} \mathrm{SDF}-1 \alpha$ and in vitro migration activities measured with transwell after 6 h. (B) Fucoxanthinol inhibited invasion of Saos-2 cells. The anti-invasive potential of fucoxanthinol was validated in Saos-2 cells using a type I collagen-coated microtiter plate. Data are mean \pm SD of triplicate experiments. In these assays, a decrease in cell index represents migration and invasion of Saos-2 cells. *P<0.05, compared with the control. (C) RT-PCR showed higher levels of MMP-1 mRNA expression in Saos-2 and $143 \mathrm{~B}$ cell lines than MNNG cells. (D) Fucoxanthinol inhibited MMP-1 expression in Saos-2 cells. Cells were treated with the noted concentrations of fucoxanthinol for the indicated time intervals and the protein expression of MMP-1 was examined by western blot analysis.

PDK1. Fucoxanthinol inhibited the phosphorylation of PDK1, but not the total PDK1 (Fig. 6).

Fucoxanthinol inhibits cell migration and invasion. Osteosarcoma is characterized by a high metastatic potential. The chemokine SDF- $1 \alpha$ and its receptor CXCR4, play a crucial role in adhesion and migration of osteosarcoma cells (25). Fucoxanthinol inhibited SDF-1 $\alpha$-induced migration of Saos-2 cells in a dose-dependent manner (Fig. 7A). The effect of fucoxanthinol on invasion of Saos- 2 cells was examined by using a type I collagen-coated transwell cell culture chambers. Saos-2 cells moved from the top chamber to the bottom chamber in the absence of fucoxanthinol, but the penetration of type I collagen-coated filter by Saos-2 cells was inhibited in the presence of fucoxanthinol (Fig. 7B).

We have recently reported that MMP-1, otherwise known as collagenase-1, plays important roles in invasion of osteosarcoma cells (26). MMP-1 was highly expressed in the high-frequent pulmonary metastatic human osteosarcoma cell line 143B compared with MNNG cells (26). Saos-2 cells also expressed MMP-1 mRNA (Fig. 7C) and fucoxanthinol inhibited such expression in a time- and dose-dependent manner (Fig. 7D).

Fucoxanthinol inhibits AP-1 activation. We reported previously that AP-1 signaling pathway upregulates the expression of MMP-1 (26). EMSA was performed with a double-stranded oligonucleotide representing the AP-1 element in the MMP-1 promoter. A protein complex bound to the AP-1 site was detected in nuclear extracts from Saos-2 cells (Fig. 8A, lane 1). The specificity of DNA-protein complex formation was assessed by competition studies with unlabeled competitors. As expected, a 'cold' MMP-1 wild-type AP-1 oligonucleotide or an AP-1 site from the IL-8 promoter effectively competed with
A Competitor

MMP-1 AP-1

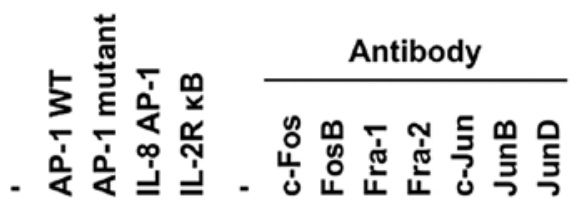

B

Fucoxanthinol $(20 \mu \mathrm{M})$

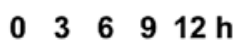

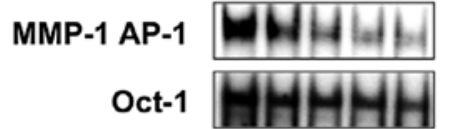

Figure 8. AP-1 binding site mediated fucoxanthinol-induced downregulation of MMP-1. (A) EMSA using AP-1 oligonucleotide from the MMP-1 promoter. Nuclear protein $(5 \mu \mathrm{g})$ extracted from Saos-2 cells was incubated with a radioactively labeled AP-1 oligonucleotide. DNA-protein complexes were resolved on polyacrylamide gel electrophoresis. Unlabeled wild-type (WT) and mutant AP-1 or NF- $\mathrm{kB}$ oligonucleotides were used as competitors for complex formation. Antibodies against specific AP-1 components were used in supershift experiments to determine the nature of the DNA-protein complex. Arrow, specific AP-1-DNA binding complex. Arrowheads, supershifted DNA-protein complexes. (B) Effect of fucoxanthinol on activation of AP-1 in Saos-2 cells. Nuclear extracts from cells cultured with fucoxanthinol $(20 \mu \mathrm{M})$ for the indicated time intervals were analyzed by EMSA.

the labeled MMP-1 AP-1 probe and eliminated the binding of nuclear extracts from Saos-2 cells (Fig. 8A, lanes 2 and 4). In contrast, the unlabeled MMP-1 AP-1 mutant or consensus 
A

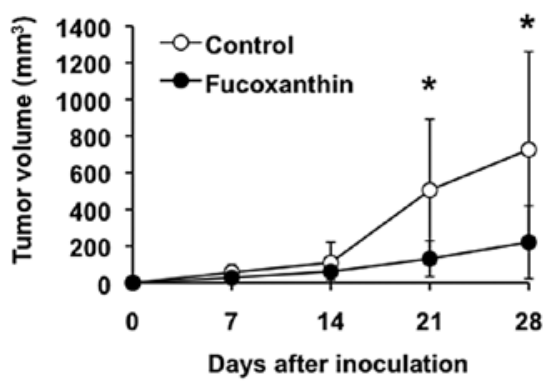

D

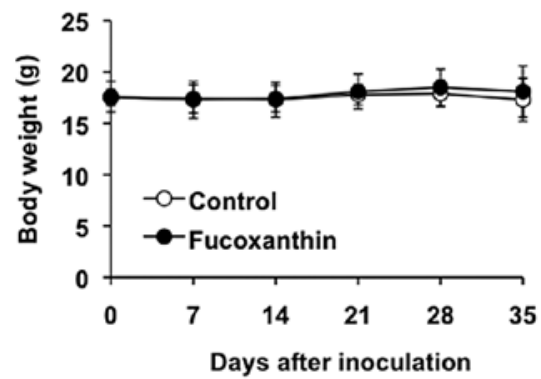

B

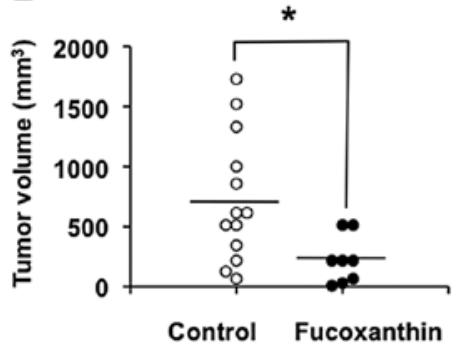

$\mathbf{E}$
C

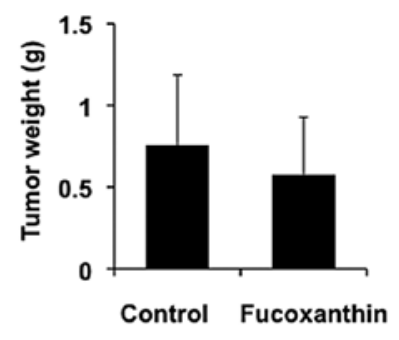

Day 35

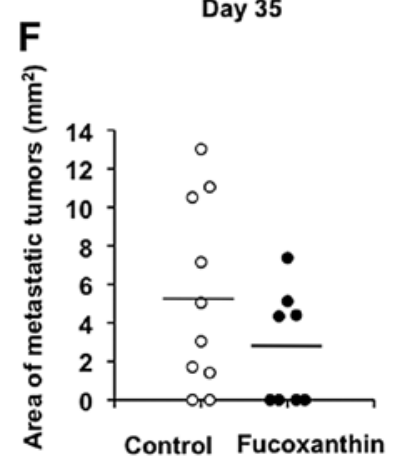

Figure 9. Inhibition of development of tumors and appearance of pulmonary metastases by fucoxanthin. LM8 cells were inoculated subcutaneously into the back of C3H mice on day 0 . The mice were treated orally with $200 \mathrm{mg} / \mathrm{kg} / \mathrm{day}$ of fucoxanthin or vehicle. (A) Serial changes in primary tumor volume evaluated weekly. (B) The volume of the primary tumor measured at day 28 after inoculation. The horizontal bars represent the mean value for each group. ${ }^{*} \mathrm{P}<0.05$, compared with the control. (C) Tumor weight after removal from fucoxanthin-treated mice and untreated mice at day 35 after inoculation. (D) Serial changes in body weight of mice treated as indicated. Data are mean \pm SD in each group. (E) Representative images showing gross appearance of the primary tumor (top panel) and lungs (bottom panel) of mice treated (right) or untreated (left) with fucoxanthin on day 35. (F) Area of lung metastasis in vehicle-treated and fucoxanthin-treated mice. The horizontal bars represent the mean area of each group.

A

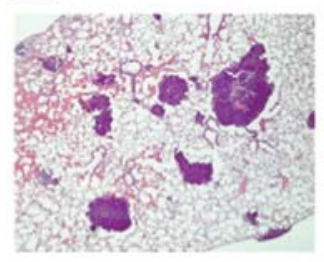

Control (\#11)

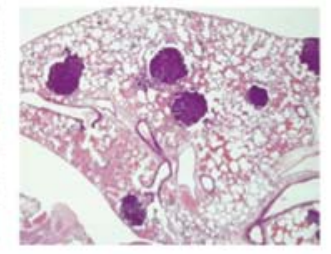

B

Control (\#2)
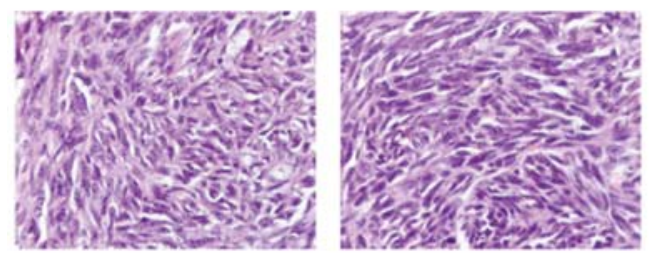

C

Control (\#2)

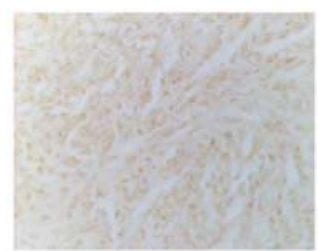

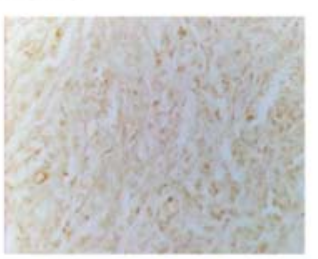

Fucoxanthin (\#14)
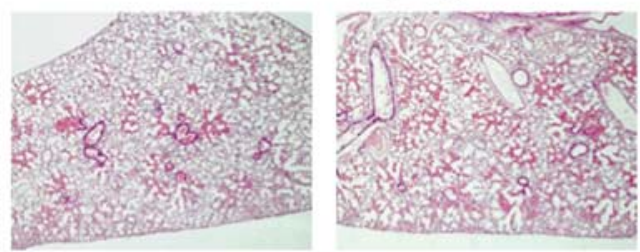

Fucoxanthin (\#17)
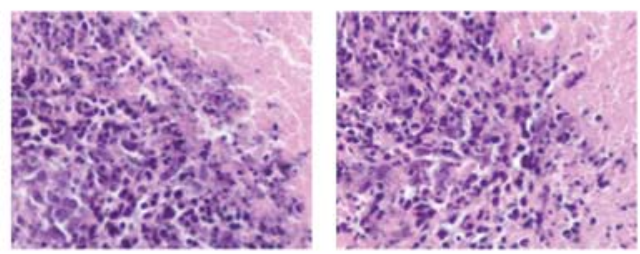

Fucoxanthin (\#17)

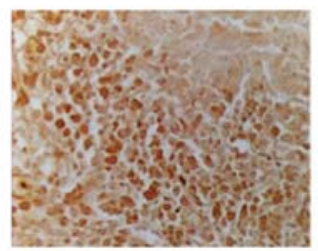

Figure 10. Increased apoptotic cells in the primary tumor and inhibition of pulmonary metastases by fucoxanthin. LM8 cells were inoculated subcutaneously into the back of $\mathrm{C} 3 \mathrm{H}$ mice on day 0 . The mice were treated with fucoxanthin or vehicle every day. On day 35 , the primary tumor and lungs were removed. (A) Representative microscopic photographs of the lungs (H\&E staining) of mice untreated (left panels) and treated with (right panels) fucoxanthin on day 35 showing the presence of metastatic nodules in the lungs of untreated mice. Magnification, x50. H\&E staining (B) and TUNEL assay (C) of sections of the primary tumor of mice untreated (left panels) and treated (right panels) with fucoxanthin on day 35. Magnification, x400. 
Table I. C3H mice inoculated with LM8 cells.

\begin{tabular}{|c|c|c|c|}
\hline $\begin{array}{l}\text { Mouse } \\
\text { no. }\end{array}$ & Treatment & $\begin{array}{l}\text { Lung metastases } \\
\text { at } 35 \text { days }\end{array}$ & Survival \\
\hline 1 & Control & + & Alive \\
\hline 2 & Control & ++ & Alive \\
\hline 3 & Control & + & Alive \\
\hline 4 & Control & $\mathrm{NE}$ & Dead $^{\mathrm{a}}$ \\
\hline 5 & Control & ++ & Alive \\
\hline 6 & Control & +++ & Alive \\
\hline 7 & Control & - & Alive \\
\hline 8 & Control & ++ & Alive \\
\hline 9 & Control & NE & Dead $^{\mathrm{a}}$ \\
\hline 10 & Control & $\mathrm{NE}$ & Dead $^{a}$ \\
\hline 11 & Control & ++ & Alive \\
\hline 12 & Control & ++ & Alive \\
\hline 13 & Control & - & Alive \\
\hline Total & & $8 / 10(80 \%)$ & $10 / 13(77 \%)$ \\
\hline 14 & Fucoxanthin & - & Alive \\
\hline 15 & Fucoxanthin & - & Alive \\
\hline 16 & Fucoxanthin & + & Alive \\
\hline 17 & Fucoxanthin & ++ & Alive \\
\hline 18 & Fucoxanthin & - & Alive \\
\hline 19 & Fucoxanthin & - & Alive \\
\hline 20 & Fucoxanthin & ++ & Alive \\
\hline 21 & Fucoxanthin & + & Alive \\
\hline Total & & $4 / 8(50 \%)$ & $8 / 8(100 \%)$ \\
\hline
\end{tabular}

${ }^{a}$ Mice died between days 28 and 35 after inoculation. The level of lung metastasis was scored as numerous $(+++)$, moderate $(++)$, small (+), or absent (-). NE, not examined.

$\mathrm{NF}-\kappa \mathrm{B}$ site from the IL-2R $\alpha$ promoter could not compete with the labeled AP-1 probe (Fig. 8A, lanes 3 and 5). The exact composition of the transcription factor DNA-protein complex in Saos-2 cells was analyzed by supershift assay using specific antibodies. These experiments identified Fra-2, c-Jun and JunD as the predominant components of the AP-1 complex on the MMP-1 AP-1 site in Saos-2 cells (Fig. 8A, lanes 10, 11 and 13). Fucoxanthinol decreased the protein complex bound to the AP-1 site in nuclear extracts derived from Saos-2 cells and such effect was time-dependent (Fig. 8B), suggesting that fucoxanthinol suppressed the invasion of Saos-2 cells by suppressing the AP-1 signaling pathway. The inhibitory effect also appeared specific to AP-1 and not related to cell death, because no significant change in binding of Oct-1 was observed after treatment with fucoxanthinol.

Fucoxanthin reduces primary tumor size and pulmonary metastasis in mice. Inoculation of the murine osteosarcoma cell line, $\mathrm{LM} 8$, into the skin of $\mathrm{C} 3 \mathrm{H}$ mice results in the formation of tumors with high metastatic potential to the lung (27). We assessed the antitumor activity of fucoxanthin using this

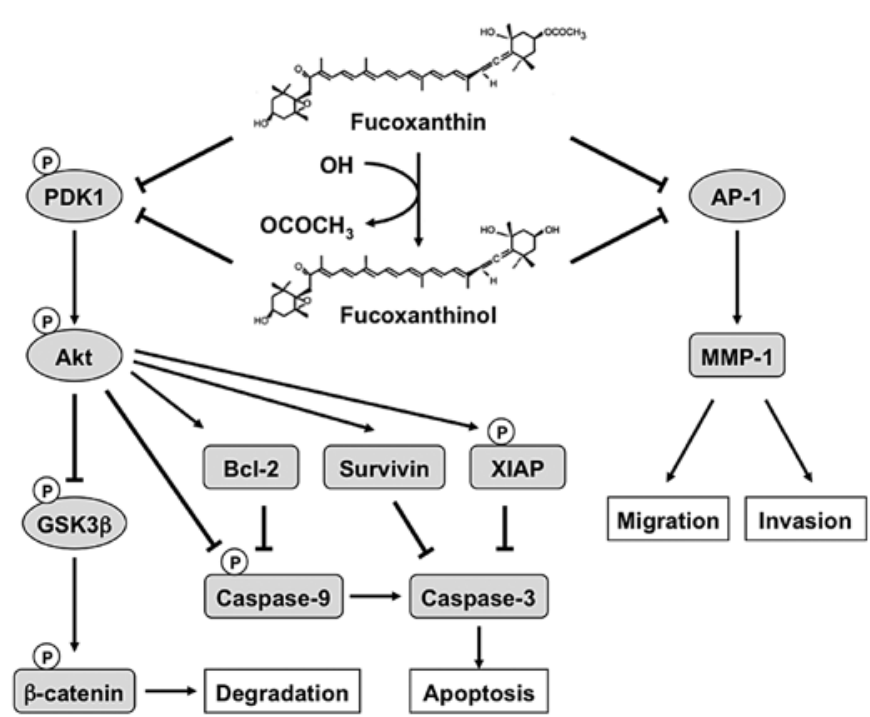

Figure 11. A diagram summarizing the actions of fucoxanthin and fucoxanthinol described in this study.

model. Subcutaneous inoculation of LM8 cells was followed by the appearance of tumors that exhibited rapid growth, reaching $726 \mathrm{~mm}^{3}$ in size within 4 weeks (Fig. 9A and B). Three of 13 mice inoculated with LM8 cells died between 4 and 5 weeks after inoculation (Table I). Multiple metastatic nodules were found macroscopically and confirmed histopathologically in the lungs of 8 of 10 LM8-inoculated mice $(80 \%)$ at 5 weeks after inoculation (Table I, Fig. 9E, bottom panel, left and $10 \mathrm{~A}$, left panels). Treatment of these mice with $200 \mathrm{mg} / \mathrm{kg} /$ day of fucoxanthin after inoculation of LM8 showed significant reduction of the primary tumor volume associated with increased apoptotic cells in the tumor as judged by $\mathrm{H} \& \mathrm{E}$ staining and TUNEL assay (Fig. 9A, B and E, top panel, right, $10 \mathrm{~B}$ and $\mathrm{C}$, right panels), although the difference in tumor weight after 5 weeks of treatment, compared with control, was less conspicuous (Fig. 9C). The mean tumor volume was lower in mice treated with fucoxanthin than with control, albeit statistically insignificant after 5 weeks of treatment, because the 3 untreated mice with huge tumors died between 4 and 5 weeks after inoculation (data not shown). Although 4 of 8 fucoxanthin-treated mice (50\%) had visible gross lung nodules, all mice were still alive at 5 weeks after inoculation (Table I). The area of lung metastasis in fucoxanthin-treated mice tended to be smaller than the vehicle-treated control mice but the difference was not significant (Fig. 9F). We found little difference in body weight of the fucoxanthin-treated and untreated groups (Fig. 9D) and no obvious abnormalities in the treated mice at this dosage.

\section{Discussion}

The main issue addressed by this study is whether carotenoids have any effects on osteosarcoma cells and the possible molecular mechanisms of any such effect. The results showed that fucoxanthin isolated from $C$. okamuranus Tokida and fucoxanthinol prepared by enzymatic hydrolysis of purified fucoxanthin exhibited anti-osteosarcoma properties; these 
properties appear to be at least in part attributable to the inhibition of Akt and AP-1 signal pathways in osteosarcoma cells.

In this study, we demonstrated that fucoxanthin and fucoxanthinol decreased cell viability in the 4 tested osteosarcoma cell lines in a concentration-dependent manner. The inhibitory effects of fucoxanthin and fucoxanthinol on the cell viability were remarkable compared with other carotenoids. Further, we studied the effect of fucoxanthinol on the induction of apoptosis and the results demonstrated that fucoxanthinol induced apoptosis through activation of caspases-3, -8 and -9 in Saos-2 cells. Inhibition of cell viability in Saos- 2 cells treated with fucoxanthinol was significantly diminished by the general caspase inhibitor Z-VAD-fmk. However, since Z-VAD-fmk partially diminished a decrease in cell viability, it is suggested that the apoptosis signaling in Saos-2 cells by fucoxanthinol is mediated by both caspase-dependent and -independent pathways. The apoptotic effect of fucoxanthinol was associated with suppression of expression of survivin, XIAP, Bcl-2 and Bcl- $\mathrm{X}_{\mathrm{L}}$. Dephosphorylation of p130 through the downregulation of CDK4, CDK6 and cyclin E also seems to contribute to the activation of $\mathrm{G}_{1}$ cell cycle arrest.

The Akt signaling pathway is important for cell survival and apoptosis (24). Increased Akt phosphorylation has been reported in osteosarcoma cell lines U2OS and MG63 (23). The present results showed that Akt is constitutively phosphorylated at both Ser473 and Thr308 in Saos-2 cells. Fucoxanthinol inhibited Akt phosphorylation at these two sites. As the downstream targets of Akt, GSK $3 \beta$ and caspase- 9 have been reported to be involved in the regulation of cell survival. Akt promotes cell survival by phosphorylating GSK3 $\beta$ and caspase-9, which inactivates them and prevents apoptosis (24). The results showed constitutive phosphorylation of GSK3 $\beta$ and caspase-9 in Saos- 2 cells and fucoxanthinol suppressed the phosphorylation levels. To further confirm the role of GSK3 $\beta$ in fucoxanthinol-induced apoptosis, we examined the expression of $\beta$-catenin, a downstream target of GSK $3 \beta$. The results showed that fucoxanthinol reduced the level of $\beta$-catenin. $\mathrm{NF}-\kappa \mathrm{B}$ is activated by stimulation of the I $\kappa \mathrm{B}$ kinase complex, which phosphorylates $\mathrm{I} \kappa \mathrm{B} \alpha$. I $\kappa \mathrm{B}$ kinase phosphorylation by Akt is essential for NF- $\kappa \mathrm{B}$ activation (28). However, we could not observe constitutive activation of NF- $\kappa \mathrm{B}$ in Saos- 2 cells. Basal levels of phosphorylated $\mathrm{I} \kappa \mathrm{B} \alpha$ and NF- $\mathrm{NB}$ RelA as well as NF- $\mathrm{B}$-DNA binding were not observed in Saos-2 cells (Fig. 5C and data not shown) (29). In addition, fucoxanthinol did not alter the levels of total and phosphorylated $\mathrm{I} \kappa \mathrm{B} \alpha$. Thus, fucoxanthinol-induced apoptosis is independent of $\mathrm{NF}-\kappa \mathrm{B}$. We investigated the effect of fucoxanthinol on the upstream event of Akt, PDK1. The results demonstrated that fucoxanthinol inhibited the expression of phosphorylated PDK1, but not the total level of PDK1. Akt promoted cell survival by inhibiting apoptosis through its ability to phosphorylate and inactivate several targets, which are components of the intrinsic cell death machinery, including the Bcl-2 and IAP family members. Akt can be an upstream regulator of XIAP, which possess an Akt phosphorylation site (30). Furthermore, survivin and Bcl-2 have been shown to be downstream targets of Akt signaling $(31,32)$. Thus, inhibition of Akt pathway mediates, at least in part, the induction of apoptosis and cell cycle arrest in $\mathrm{G}_{1}$ phase induced by fucoxanthinol.
The mean 5-year survival rate of patients with metastasizing osteosarcoma is only $20-30 \%$ (33). Therefore, many investigators have focused on the development of new agents for blocking cancer cell metastasis. MMPs play an important role in tumor angiogenesis, metastasis and stimulation of growth factor release from the extracellular matrices (34). We investigated the anti-metastatic functions of fucoxanthinol on the migration and invasion of Saos- 2 cells and the results indicated that fucoxanthinol can inhibit in vitro migration and invasion ability of Saos-2 cells.

Our results also showed that fucoxanthinol inhibited MMP-1 expression. MMP-1 is involved in the invasive metastatic potential of osteosarcoma cells (26). Recent studies showed that MMP-1 silencing inhibits osteosarcoma pulmonary metastases in vivo (35). Thus, inhibition of MMP-1 expression or enzyme activity can be an early target to prevent cancer metastasis. We have reported that AP-1 signaling pathway plays a crucial role in constitutive transactivation of MMP-1 in osteosarcoma cells (26). Fucoxanthinol inhibited AP-1-DNA binding activity. Taken together, our findings suggest that fucoxanthinol has anti-metastatic activities by blocking AP-1 resulting in inhibition of MMP-1.

The concentration of fucoxanthin or fucoxanthinol used in this study to exhibit anti-osteosarcoma effects may not be pharmacologically achievable in humans. Because the concentrations that induce antitumor effects in vitro often differ from those in vivo, future in vivo efficacy studies with fucoxanthin or fucoxanthinol should be conducted in animal models. In the present study, we described the antitumor properties of fucoxanthin in mice.

The novel findings of this study are that fucoxanthin and fucoxanthinol are potent inducers of apoptosis and cell cycle arrest, with anti-metastatic properties in osteosarcoma cells at least in part via inhibition of Akt and AP-1. A hypothetical model for the actions of fucoxanthin and fucoxanthinol is shown in Fig. 11. Based on these findings, it is tempting to speculate that fucoxanthin or fucoxanthinol alone or in combination with other conventional chemotherapeutics may be potentially useful in the treatment of osteosarcoma.

\section{References}

1. Savage $\mathrm{S}$ and Mirabello L: Using epidemiology and genomics to understand osteosarcoma etiology. Sarcoma 2011: 548151, 2011.

2. Anninga JK, Gelderblom H, Fiocco M, Kroep JR, Taminiau AHM, Hogendoorn PCW and Egeler RM: Chemotherapeutic adjuvant treatment for osteosarcoma: where do we stand? Eur J Cancer 47: 2431-2445, 2011.

3. Marina N, Gebhardt M, Teot L and Gorlick R: Biology and therapeutic advances for pediatric osteosarcoma. Oncologist 9: 422-441, 2004.

4. Musa-Veloso K, Card JW, Wong AW and Cooper DA: Influence of observational study design on the interpretation of cancer risk reduction by carotenoids. Nutr Rev 67: 527-545, 2009.

5. Peng J, Yuan J-P, Wu C-F and Wang J-H: Fucoxanthin, a marine carotenoid present in brown seaweeds and diatoms: metabolism and bioactivities relevant to human health. Mar Drugs 9: 1806-1828, 2011.

6. Yamamoto $\mathrm{K}$, Ishikawa $\mathrm{C}$, Katano $\mathrm{H}$, Yasumoto $\mathrm{T}$ and Mori $\mathrm{N}$ : Fucoxanthin and its deacetylated product, fucoxanthinol, induce apoptosis of primary effusion lymphomas. Cancer Lett 300: 225-234, 2011.

7. Rhim JS, Putman DL, Arnstein P, Huebner RJ and McAllister RM: Characterization of human cells transformed in vitro by N-methyl-N'-nitro-N-nitrosoguanidine. Int J Cancer 19: 505-510, 1977. 
8. Hensler PJ, Annab LA, Barrett JC and Pereira-Smith OM: A gene involved in control of human cellular senescence on human chromosome 1q. Mol Cell Biol 14: 2291-2297, 1994

9. Zhang C, Ao Z, Seth A and Schlossman SF: A mitochondrial membrane protein defined by a novel monoclonal antibody is preferentially detected in apoptotic cells. J Immunol 157: 3980-3987, 1996

10. Antalis TM and Godbolt D: Isolation of intact nuclei from hematopoietic cell types. Nucleic Acids Res 19: 4301, 1991.

11. Mori N and Prager D: Transactivation of the interleukin-1 $\alpha$ promoter by human T-cell leukemia virus type I and type II Tax proteins. Blood 87: 3410-3417, 1996.

12. Sherr CJ and Roberts JM: Living with or without cyclins and cyclin-dependent kinases. Genes Dev 18: 2699-2711, 2004.

13. Cheng L, Rossi F, Fang W, Mori T and Cobrinik D: Cdk2dependent phosphorylation and functional inactivation of the pRB-related p130 protein in $\mathrm{pRB}(-), \mathrm{p} 16^{\mathrm{INK} 4 \mathrm{~A}}(+)$ tumor cells J Biol Chem 275: 30317-30325, 2000.

14. Perkins ND: The diverse and complex roles of NF- $\kappa \mathrm{B}$ subunits in cancer. Nat Rev Cancer 12: 121-132, 2012.

15. Hayden MS and Ghosh S: Shared principles in NF- $\kappa B$ signaling. Cell 132: 344-362, 2008.

16. Iwanaga R, Ohtani K, Hayashi T and Nakamura M: Molecular mechanism of cell cycle progression induced by the oncogene product Tax of human T-cell leukemia virus type I. Oncogene 20 2055-2067, 2001.

17. Zahradka P, Werner JP, Buhay S, Litchie B, Helwer G and Thomas S: NF- $\mathrm{B}$ activation is essential for angiotensin II-dependent proliferation and migration of vascular smooth muscle cells. J Mol Cell Cardiol 34: 1609-1621, 2002

18. Zhu L, Fukuda S, Cordis G, Das DK and Maulik N: Antiapoptotic protein survivin plays a significant role in tubular morphogenesis of human coronary arteriolar endothelial cells by hypoxic preconditioning. FEBS Lett 508: 369-374, 2001.

19. Stehlik C, de Martin R, Kumabashiri I, Schmid JA, Binder BR and Lipp J: Nuclear factor (NF)- $\kappa \mathrm{B}$-regulated X-chromosomelinked iap gene expression protects endothelial cells from tumor necrosis factor $\alpha$-induced apoptosis. J Exp Med 188: 211-216, 1998.

20. Pahl HL: Activators and target genes of Rel/NF- $\mathrm{B}$ transcription factors. Oncogene 18: 6853-6866, 1999.

21. Grossmann M, O'Reilly LA, Gugasyan R, Strasser A, Adams JM and Gerondakis S: The anti-apoptotic activities of Rel and RelA required during B-cell maturation involve the regulation of Bcl-2 expression. EMBO J 19: 6351-6360, 2000.

22. Nicot C, Mahieux R, Takemoto $\mathrm{S}$ and Franchini G: Bcl- $\mathrm{X}_{\mathrm{L}}$ is up-regulated by HTLV-I and HTLV-II in vitro and in ex vivo ATLL samples. Blood 96: 275-281, 2000.
23. Jin S, Pang R-P, Shen J-N, Huang G, Wang J and Zhou J-G: Grifolin induces apoptosis via inhibition of PI3K/AKT signalling pathway in human osteosarcoma cells. Apoptosis 12: 1317-1326, 2007.

24. Manning BD and Cantley LC: AKT/PKB signaling: navigating downstream. Cell 129: 1261-1274, 2007.

25. Perissinotto E, Cavalloni G, Leone F, Fonsato V, Mitola S, Grignani G, Surrenti N, Sangiolo D, Bussolino F, Piacibello W and Aglietta M: Involvement of chemokine receptor 4/stromal cell-derived factor 1 system during osteosarcoma tumor progression. Clin Cancer Res 11: 490-497, 2005.

26. Kimura R, Ishikawa C, Rokkaku T, Janknecht R and Mori N: Phosphorylated c-Jun and Fra-1 induce matrix metalloproteinase-1 and thereby regulate invasion activity of 143B osteosarcoma cells. Biochim Biophys Acta 1813: 1543-1553, 2011.

27. Asai T, Ueda T, Itoh K, Yoshioka K, Aoki Y, Mori S and Yoshikawa H: Establishment and characterization of a murine osteosarcoma cell line (LM8) with high metastatic potential to the lung. Int J Cancer 76: 418-422, 1998

28. Ozes ON, Mayo LD, Gustin JA, Pfeffer SR, Pfeffer LM and Donner DB: NF- $\kappa$ B activation by tumour necrosis factor requires the Akt serine-threonine kinase. Nature 401: 82-85, 1999.

29. Ali NN, Gilston V and Winyard PG: Activation of NF- $\kappa B$ in human osteoblasts by stimulators of bone resorption. FEBS Lett 460: 315-320, 1999.

30. Dan HC, Sun M, Kaneko S, Feldman RI, Nicosia SV, Wang H-G, Tsang BK and Cheng JQ: Akt phosphorylation and stabilization of X-linked inhibitor of apoptosis protein (XIAP). J Biol Chem 279: 5405-5412, 2004

31. Liang Y-L, Wang L-Y, Wu H, Ma D-Z, Xu Z and Zha X-L $\mathrm{PKB}$ phosphorylation and survivin expression are cooperatively regulated by disruption of microfilament cytoskeleton. Mol Cell Biochem 254: 257-263, 2003.

32. Pugazhenthi S, Nesterova A, Sable C, Heidenreich KA, Boxer LM, Heasley LE and Reusch JE-B: Akt/protein kinase B up-regulates Bcl-2 expression through cAMP-response elementbinding protein. J Biol Chem 275: 10761-10766, 2000.

33. Longhi A, Errani C, De Paolis M, Mercuri M and Bacci G: Primary bone osteosarcoma in the pediatric age: state of the art. Cancer Treat Rev 32: 423-436, 2006.

34. Gialeli G, Theocharis AD and Karamanos NK: Roles of matrix metalloproteinases in cancer progression and their pharmacological targeting. FEBS J 278: 16-27, 2011.

35. Jawad MU, Garamszegi N, Garamszegi SP, Correa-Medina M, Diez JA, Wen R and Scully SP: Matrix metalloproteinase 1: role in sarcoma biology. PLoS One 5: e14250, 2010. 